\title{
Antimicrobial resistance and antimicrobial use associated with laboratory-confirmed cases of Campylobacter infection in two health units in Ontario
}

\author{
Anne E Deckert DVM MS ${ }^{1,2}$, Richard J Reid-Smith DVM DVSc ${ }^{1,2}$, Susan E Tamblyn MD ${ }^{3}$, Larry Morrell RN BScN ${ }^{4}$, \\ Patrick Seliske $\mathrm{PhD}^{5}$, Frances B Jamieson MD FRCPC ${ }^{6}$, Rebecca Irwin DVM MS ${ }^{2}$, Catherine E Dewey DVM PhD ${ }^{1}$, \\ Patrick Boerlin DVM MSc ${ }^{7}$, Scott A McEwen DVM DVSc ${ }^{1}$
}

\begin{abstract}
AE Deckert, RJ Reid-Smith, SE Tamblyn, et al. Antimicrobial resistance and antimicrobial use associated with laboratoryconfirmed cases of Campylobacter infection in two health units in Ontario. Can J Infect Dis Med Microbiol 2013;24(1):e16-e21.
\end{abstract}

\begin{abstract}
AIM: A population-based study was conducted over a two-year period in the Perth District (PD) and Wellington-Dufferin-Guelph (WDG) health units in Ontario to document antimicrobial resistance and antimicrobial use associated with clinical cases of laboratory-confirmed campylobacteriosis.

METHODS: Etest (bioMérieux SA, France) was used to determine the minimum inhibitory concentration of amoxicillin/clavulanic acid, ampicillin, chloramphenicol, ciprofloxacin (CIP), clindamycin, erythromycin (ERY), gentamicin, nalidixic acid and tetracycline. Data regarding antimicrobial use were collected from 250 cases.

RESULTS: Of the 250 cases, 165 (65.7\%) reported staying home or being hospitalized due to campylobacteriosis. Fifty-four per cent of cases (135 of 249) reported taking antimicrobials to treat campylobacteriosis. In 115 cases $(51.1 \%)$, fecal culture results were not used for treatment decisions because they were not available before the initiation of antimicrobial treatment and/or they were not available before the cessation of symptoms. Of the 250 cases, 124 (49.6\%) had available Campylobacter isolates, of which 66 (53.2\%) were resistant to at least one of the antimicrobials tested. No resistance to ampicillin, chloramphenicol or gentamicin was found in these isolates. Six isolates $(4.8 \%)$ were resistant to CIP. Two isolates $(1.6 \%)$ were resistant to ERY; however, no isolates were resistant to both CIP and ERY.

CONCLUSION: Prudent use practices should be promoted among physicians to reduce the use of antimicrobials for the treatment of gastroenteritis in general and campylobacteriosis in particular, as well as to minimize the future development of resistance to these antimicrobials in Campylobacter species.
\end{abstract}

Key Words: Antimicrobial resistance; Antimicrobial use; Campylobacter; Canada; Ontario

ampylobacter species are an important human enteric pathogen that can cause severe, bloody diarrhea, fever and abdominal pain $(1,2)$. In Canada, the National Notifiable Disease Program reported 31.8 isolations of Campylobacter per 100,000 people in the province of Ontario and 30.2 per 100,000 people nationally in 2004, which is the most recent year for which results are available (3). In 2004, there were 3945 and 9345 campylobacteriosis cases reported in Ontario and Canada, respectively (3). In 2009,

\section{La résistance antimicrobienne et l'utilisation d'antimicrobiens associées à des cas de Campylobacter confirmés en laboratoire dans deux unités de santé de l'Ontario}

\begin{abstract}
OBJECTIF : Les chercheurs ont mené une étude en population pendant une période de deux ans dans les unités sanitaires du district de Perth et de Wellington-Dufferin-Guelph en Ontario, afin d'étayer la résistance antimicrobienne et l'utilisation d'antimicrobiens associées à des cas cliniques de campylobactériose confirmés en laboratoire.

MÉTHODOLOGIE : Les chercheurs ont utilisé l'Etest (bioMérieux SA, France) pour déterminer la concentration inhibitrice minimale d'amoxicilline-acide clavulanique, d'ampicilline, de chloramphénicol, de ciprofloxacine (CIP), de clindamycine, d'érythromycine (ERY), de gentamicine, d'acide nalidixique et de tétracycline. Ils ont colligé les données sur l'utilisation d'antimicrobiens auprès de 250 cas.

RÉSULTATS : Sur les 250 cas, 165 (65,74\%) ont déclaré être restés à la maison ou avoir été hospitalisés en raison de leur campylobactériose. Cinquante-quatre pour cent des cas (135 sur 249) ont déclaré avoir pris des antimicrobiens pour traiter leur campylobactériose. Dans 115 cas (51,1\%), les résultats de la coproculture n'ont pas été utilisés pour prendre les décisions thérapeutiques parce qu'ils n'étaient pas disponibles avant l'amorce du traitement antimicrobien ou avant l'arrêt des symptômes. Sur les 250 cas, 124 (49,6 \%) disposaient d'isolats du Campylobacter, dont 66 (53,2\%) étaient résistants à au moins un des antimicrobiens testés. Les chercheurs n'ont relevé aucun cas de résistance à l'ampicilline, au chloramphénicol ou à la gentamicine dans ces isolats. Six (4,8 \%) étaient résistants à la CIP et deux (1,6\%), à l'ERY, mais aucun n'était résistant à la fois à la CIP et à l'ERY.

CONCLUSION : Il faudrait promouvoir des pratiques d'utilisation prudentes chez les médecins pour réduire l'utilisation d'antimicrobiens dans le traitement de la gastroentérite en général et de la campylobactériose en particulier, ainsi que pour limiter le plus possible l'apparition future de résistance à ces antimicrobiens dans les espèces de Campylobacter.
\end{abstract}

${ }^{1}$ Department of Population Medicine, University of Guelph; ${ }^{2}$ Laboratory for Foodborne Zoonoses, Public Health Agency of Canada, Guelph;

${ }^{3}$ Public Health Consultant; ${ }^{4}$ Perth District Health Unit, Stratford; ${ }^{5}$ Wellington-Dufferin-Guelph District Health Unit, Guelph; ${ }^{6}$ Public Health

Ontario, Toronto; ${ }^{7}$ Department of Pathobiology, University of Guelph, Guelph, Ontario

Correspondence: Dr Anne E Deckert, Laboratory for Foodborne Zoonoses, Public Health Agency of Canada, 160 Research Lane, 103, Guelph,

Ontario N1G 5B2. Telephone 519-826-2160, fax 519-826-2255, e-mail adeckert@uoguelph.ca 
The case fatality rate for Campylobacter infection was reported to be one in 1000 in the US in 1999 (8). It has been estimated that 9\% to $14 \%$ of cases develop postinfectious irritable bowel syndrome $(9,10)$ and approximately one in 1000 cases progress to Gullain-Barré syndrome (11).

Campylobacteriosis is usually a self-limiting infection and treatment is recommended only in vulnerable populations with severe or invasive disease $(12,13)$. However, observational studies have shown that a substantial percentage of patients are prescribed antimicrobials to treat campylobacteriosis (14-17). There is currently no information regarding the types and prevalence of antimicrobial treatment for campylobacteriosis in Canada. Erythromycin (ERY) is commonly used in both adults and children, and fluoroquinolones, such as ciprofloxacin (CIP), are used in adult cases (12). There is also evidence in the literature that antimicrobial resistance in Campylobacter may be associated with increased virulence and adverse outcomes in human cases (18) as well as a prolonged duration of diarrhea $(16,19,20)$. Therefore, resistance in Campylobacter organisms to antimicrobials in general, and these clinically important antimicrobials in particular, is of concern.

A population-based study was conducted over a two-year period in the Perth District (PD) and Wellington-Dufferin-Guelph (WDG) health units of Ontario to document antimicrobial resistance and antimicrobial use associated with clinical cases of campylobacteriosis.

\section{METHODS}

The present research project was approved by the University of Guelph Research Ethics Board (Guelph, Ontario). Agreements with hospital and private laboratories were established that enabled the isolates obtained from clients living in these health unit areas to be forwarded for further characterization to the Central Public Health Laboratory (CPHL, Toronto, Ontario), Ontario Ministry of Health and Long-term Care (now the Public Health Ontario Laboratory, Toronto, Ontario). These agreements ensured the confidentiality of patient information. Case physicians were not provided with the results of the further characterization conducted for the present research project. The testing delays inherent in a research project precluded the results from being available in a clinically relevant time-frame.

\section{Cases}

Laboratory confirmed cases of Campylobacter infection occurring between February 2002 and February 2004 that resided in the PD and WDG health unit areas were eligible for inclusion in the study. Cases were excluded if the patient could not speak English or did not have a home telephone. Patients were informed of the purpose of the study and provided informed consent for participation at the time of questionnaire administration. Questionnaires were administered by health unit personnel via telephone.

\section{Study area}

The average population of the PD and WDG health unit areas during the time period of the study was 77,188 and 252,844, respectively. Both health unit areas have a combination of urban and rural populations.

\section{Isolation \\ Campylobacter strains were confirmed and speciated at the CPHL using Gram-stain, the oxidase test, hippurate hydrolysis, susceptibility to nalidixic acid (NAL) $(30 \mu \mathrm{g})$ and cephalothin $(30 \mu \mathrm{g})$, microaerophilic growth at $25^{\circ} \mathrm{C}, 36^{\circ} \mathrm{C}$ and $42^{\circ} \mathrm{C}$, aerobic growth at $25^{\circ} \mathrm{C}$, catalase pro- duction and indoxyl acetate hydrolysis. Supplementary tests included urea hydrolysis, nitrate reduction, $\mathrm{H}_{2} \mathrm{~S}$ production, and growth on $1 \%$ glycine and on MacConkey agar.}

\section{Minimum inhibitory concentration}

The Etest (bioMérieux SA, France) was used for the determination of the minimum inhibitory concentration (MIC) in the isolates of amoxicillin/clavulanic acid (AMC), ampicillin (AMP), chloramphenicol (CHL), CIP, clindamycin (CLI), ERY, gentamicin (GEN), NAL and tetracycline (TCY). Subcultures were grown on Mueller-Hinton blood agar plates for $24 \mathrm{~h}$ under microaerobic conditions at $42^{\circ} \mathrm{C}$ before

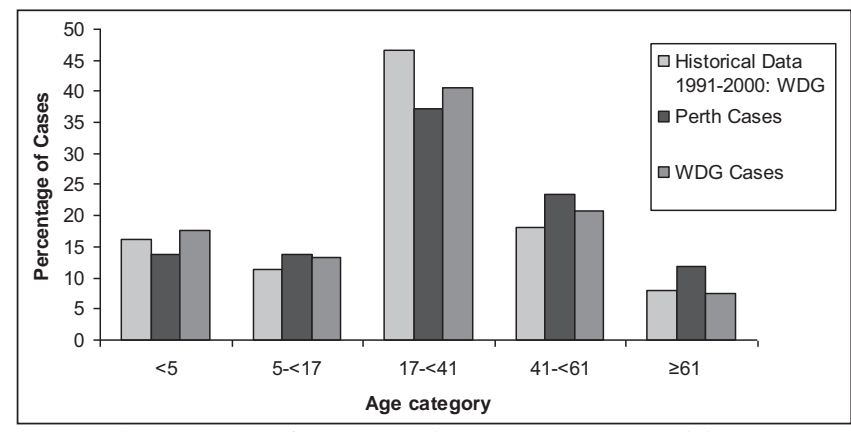

Figure 1) Percentage of cases according to age category in laboratory confirmed cases of Campylobacter infection in the Perth District (Ontario) and Wellington-Dufferin-Guelph (WDG) (Ontario) health units during the study period as well as in the WDG health unit over a 10-year period

determining the MICs using Mueller-Hinton blood agar plates with $5 \%$ laked horse blood and microaerobic conditions with incubation for $48 \mathrm{~h}$ at $37^{\circ} \mathrm{C}$. Control strains were Campylobacter jejuni American Type Culture Collection (ATCC) 33560, Escherichia coli ATCC 25922 and Staphylococcus aureus ATCC 29213. Breakpoints from the Clinical and Laboratory Standards Institute (CLSI, Wayne, Pennsylvania) and the Canadian Integrated Program for Antimicrobial Resistance Surveillance (CIPARS) were used in the present study. CIPARS breakpoints are based on CLSI guidelines when available (21). The breakpoints used were $\mathrm{AMC} \geq 32 \mu \mathrm{g} / \mathrm{mL}$, AMP $\geq 32 \mu \mathrm{g} / \mathrm{mL}$, CHL $\geq 32 \mu \mathrm{g} / \mathrm{mL}$, CIP $\geq 4 \mu \mathrm{g} / \mathrm{mL}$, CLI $\geq 4 \mu \mathrm{g} / \mathrm{mL}$, ERY $\geq 32 \mu \mathrm{g} / \mathrm{mL}$, GEN $\geq 16 \mu \mathrm{g} / \mathrm{mL}$, NAL $\geq 32 \mu \mathrm{g} / \mathrm{mL}$ and $\mathrm{TCY} \geq 16 \mu \mathrm{g} / \mathrm{mL}$.

\section{Questionnaire data}

The dates of fecal collection and availability of culture results to the physician were reported to the health unit by the primary laboratory. Information regarding the use of antimicrobials during the course of Campylobacter infection was collected as part of a comprehensive case questionnaire, which also collected information on sex, age and severity of illness. Severity of illness was reported for cases according to the following definitions: Quite mild - feeling slightly unwell but able to do all normal activities; Fairly mild - feeling quite unwell but able to do most normal activities; Moderate - having to stay at home but able to get out of bed for limited activities; Fairly severe - confined to bed at home and unable to do any normal activities; and Quite severe - hospitalized. Age was categorized according to the age distribution of Campylobacter cases reported in the WDG health unit from 1991 to 2000: <5 years of age, five to $<17$ years of age, 17 to $<41$ years of age, 41 to $<61$ years of age and $\geq 61$ years of age (Figure 1 ).

\section{Data analysis}

Test results and antimicrobial use information were analyzed using Stata Intercooled version 11 (Stata Corporation, USA). Dichotomous variables were analyzed using the $\chi^{2}$ and Fisher's exact tests as appropriate. Differences between groups of continuous variables were evaluated using the Student's $t$ test; $P<0.05$ was considered to be statistically significant.

\section{RESULTS}

There were 317 laboratory-confirmed cases during the study period, with 49.4 cases per 100,000 people in 2002 and 46.7 cases per 100,000 people in 2003. There was a marked difference in this rate between the two health units, with 84.5 cases per 100,000 people and 63.3 cases per 100,000 people in the PD health unit in 2002 and 2003, respectively, compared with 38.6 cases per 100,000 people and 41.7 cases per 100,000 people in the WDG health unit in 2002 and 2003, respectively $(P<0.05)$. Seventy-nine per cent of the cases $(n=252)$ were successfully contacted and agreed to participate. Two cases were excluded: one due to an inability to communicate in English and one did not reside in the study area. Therefore, questionnaire data were collected from 250 cases, 51 from the PD health unit area and 199 from the WDG health unit area. 


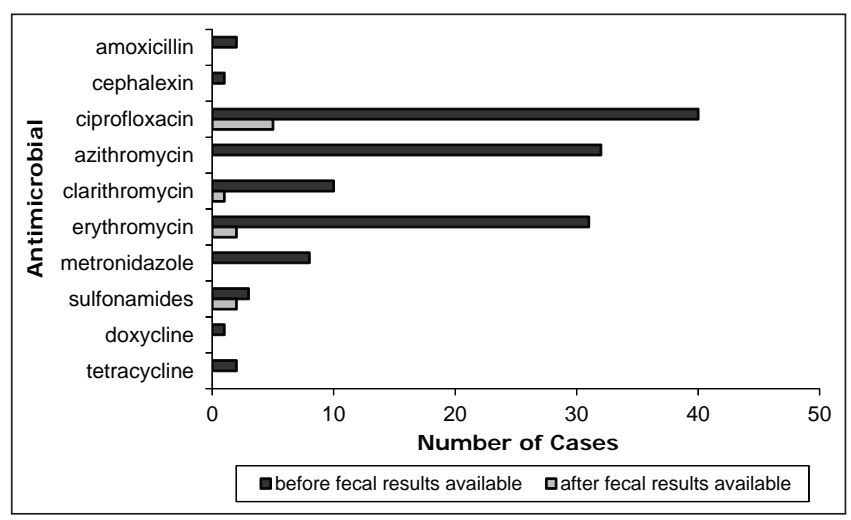

Figure 2) Frequency and timing of antimicrobial use relative to the availability of fecal culture results in laboratory-confirmed cases of Campylobacter infection in the Perth District and Wellington-Dufferin-Guelph (Ontario) health units $(n=138)$

\section{TABLE 1}

Antimicrobial resistance in Campylobacter isolates from human cases in the Perth District and Wellington-DufferinGuelph health units (Ontario)

\begin{tabular}{llllc}
\hline & \multicolumn{2}{c}{ MIC50, MIC90, } & \multicolumn{2}{c}{ Resistant isolates } \\
\cline { 5 - 6 } Antimicrobial & $\boldsymbol{\mu g} / \mathrm{mL}$ & $\boldsymbol{\mu g} / \mathrm{mL}$ & $\mathbf{n}$ & $\%(95 \% \mathrm{Cl})$ \\
\hline Amoxicillin/clavulanic acid & 0.19 & 0.38 & 0 & $0(0.0-2.9)$ \\
Ampicillin & 1.0 & 4.0 & 3 & $2.4(0.5-6.9)$ \\
Chloramphenicol & 0.75 & 1.5 & 0 & $0(0.0-2.9)$ \\
Ciprofloxacin & 0.047 & 0.094 & 6 & $4.8(1.8-10.2)$ \\
Clindamycin & 0.094 & 0.25 & 2 & $1.6(0.2-5.7)$ \\
Erythromycin & 0.25 & 0.75 & 2 & $1.6(0.2-5.7)$ \\
Gentamicin & 0.25 & 0.38 & 0 & $0(0.0-2.9)$ \\
Nalidixic acid & 1.5 & 3.0 & 6 & $4.8(1.8-10.2)$ \\
Tetracycline & 0.19 & $>256$ & 60 & $48.4(39.3-57.5)$ \\
\hline
\end{tabular}

MIC50 Minimum inhibitory concentration required to inhibit the growth of $50 \%$ of organisms; MIC90 MIC required to inhibit the growth of $90 \%$ of organisms

The age of the cases ranged from four months to 85 years, with a median age of 27.4 years. The age of cases was not significantly different between the health units $(\mathrm{P}>0.05)$. There were $140(56.2 \%)$ male cases and 109 (43.8\%) female cases, resulting in a male case to female case ratio of 1.3 to 1 . In both 2002 and 2003, more than one-half of all the cases reported that symptoms began between June and September (2002: 72 of 119 [61\%]; 2003: 68 of 122 [56\%]). The months with the highest number of cases in both years were July (2002: $n=27 ; 2003$ : $\mathrm{n}=18$ ) and September (2002: $\mathrm{n}=21 ; 2003: \mathrm{n}=18)$. Forty-eight per cent of cases (114 of 237) reported blood in the stool, but the proportion of cases with blood in the stool was significantly higher for those $<5$ years of age $(\mathrm{P}=0.001)$. Fever was reported in $73 \%$ (180 of 246$)$ of cases, 84 cases (34\%) reported Quite mild or Fairly mild symptoms and 165 cases (66\%) reported staying home or being hospitalized due to their campylobacteriosis. The overall mean number of days that cases reported having symptoms was 10 (median [ \pm SD] $8 \pm 8.6$ days).

Fifty-two per cent of cases (130 of 249) reported taking antimicrobials to treat campylobacteriosis. Cases treated using antimicrobials did not differ from those that were not treated using antimicrobials with regard to age category, severity of illness, chronic medical condition or history of recent international travel $(\mathrm{P}>0.05)$. Cases reporting blood in the stool were not more likely to be treated with antimicrobials $(\mathrm{P}=0.30)$, but cases reporting fever were more likely to be treated $(\mathrm{P}=0.004)$. The mean number of days from the onset of symptoms to the collection of the fecal sample was 6.01 (median $4 \pm 9.00$ days), to the availability of the results of the fecal culture was 12.26 (median $10 \pm 10.35$ days) and to the beginning of antimicrobial treatment was 9.81 (median $8 \pm 10.08$ days). The mean number of days from collection of the fecal sample until tests results were available was 6.33 (median $5 \pm 4.35$ days).
TABLE 2

Antimicrobial resistance patterns in Campylobacter isolates from human cases in the Perth District and Wellington-Dufferin-Guelph health units (Ontario)

\begin{tabular}{lc}
\hline Resistance profile & Isolates, $\mathbf{n}$ (\%) \\
\hline Ciprofloxacin/nalidixic acid/tetracycline & $3(2.4)$ \\
Clindamycin/erythromycin/tetracycline & $2(1.6)$ \\
Ciprofloxacin/nalidixic acid & $3(2.4)$ \\
Ampicillin & $3(2.4)$ \\
Tetracycline & $55(44.4)$ \\
Susceptible & $58(46.8)$ \\
\hline
\end{tabular}

Of the 227 cases for which there were known dates for when symptoms ended and fecal culture results were received at the health unit, 43 had culture results available on the day symptoms ended (18.9\%) and 136 (59.9\%) did not have culture results until after symptoms had ended. Therefore, in 179 cases $(78.9 \%)$ fecal culture results were not available for use in making treatment decisions. Thirty-two cases (24.4\%) began taking antimicrobials after symptoms had resolved.

Of the 96 cases for which the date of data collection was available and that also took antimicrobials before symptoms had ended, $11(11.5 \%)$ began antimicrobial treatment before the collection of the fecal sample and $20(20.8 \%)$ began antimicrobial treatment on the same day that the fecal sample was collected. Overall, 77 cases $(77.8 \%)$ began antimicrobial treatment before the results of the fecal sample became available.

The antimicrobials taken by 138 cases to treat campylobacteriosis included: AMC $(n=2)$, cephalexin $(n=1)$, CIP $(n=45)$, azithromycin $(n=32)$, clarithromycin $(n=11)$, ERY $(n=32)$, metronidazole $(n=7)$, sulfonamides $(n=5)$, doxycycline $(n=1)$ and TCY $(n=2)$ (Figure 2). Eight cases reported treatment using more than one antimicrobial. Of the cases which began antimicrobial treatment after fecal culture results were available, seven were treated using CIP, three with ERY, one with trimethoprim-sulfamethoxazole (SXT), one with azithromycin and one with clarithromycin.

Campylobacter isolates from 124 of 250 cases $(49.6 \%)$ were received by the CPHL and, therefore, had antimicrobial susceptibility information. Of these, 121 (97.6\%) were C jejuni and three (2.4\%) were Campylobacter coli. Isolates from the remaining cases were not available from the primary laboratory or were unable to be matched using case information. There were no significant differences in age category, sex or severity of illness between cases with and without accompanying isolates $(\mathrm{P}>0.05)$. There were also no significant differences between health units in the proportion of cases with accompanying isolates $(\mathrm{P}>0.05)$. Among cases with isolate susceptibility results that were treated using CIP, ERY, clarithromycin and/or azithromycin, only $5.3 \%$ ( 3 of 57 ) were resistant to the antimicrobial class used.

Sixty-six isolates $(53.2 \%)$ were resistant to at least one of the nine antimicrobials tested, including all three $\mathrm{C}$ coli isolates. Six isolates (4.8\%, five C jejuni, one C coli) were resistant to CIP (Table 1$)$ and all isolates resistant to NAL were also resistant to CIP. Two isolates (1.6\%, one $\mathrm{C}$ jejuni, one $\mathrm{C}$ coli) were resistant to ERY; however, no isolates were resistant to both CIP and ERY (Table 2).

The three cases with a $\mathrm{C}$ coli isolate did not appear to be substantially different than the cases with a $\mathrm{C}$ jejuni isolate with respect to the parameters described in the present study. All three cases were adult men; one was from the WDG health unit and two were from the PD health unit. Two of these cases had blood in the stool and one reported fever. One of these cases had travelled internationally. Severity was evenly distributed among the Fairly mild, Moderate and Fairly severe categories. Two of the cases used CIP to treat their illness and the use began before the availability of fecal culture results. The median duration of illness was four days (range four to seven days) for these three cases. 


\section{DISCUSSION}

Campylobacteriosis is usually a self-limiting disease and antimicrobial treatment is not recommended in uncomplicated cases; however, macrolides and fluoroquinolones are the primary antimicrobials used for the treatment of campylobacteriosis in vulnerable populations $(12,13,22)$. Antimicrobials may also be used in conjunction with infectious control practices in daycare or other group settings to decrease the duration of excretion and minimize person-to-person transmission; however, adequate hygiene and infection control practices are the preferred control measures (23-28).

Although only limited data are available, the percentage of campylobacteriosis cases treated using antimicrobials varied in published studies: $16 \%$ in a study conducted in Norway (14), $54 \%$ in the present study, $74 \%$ in a study conducted in Finland (17) and $81 \%$ to $83 \%$ in a study conducted in the US $(15,16)$.

The mean and median number of days in the present study from the onset of symptoms to antimicrobial treatment (mean 9.8 days; median eight days) were slightly lower than what was reported in a study conducted in Norway (mean 11.3 days; median 10 days) (14). Also, the mean and median number of days from the onset of symptoms to the submission of a fecal sample (mean six days, median four days) were somewhat lower than reported in a previously published study (mean nine days; median six days) (14) but similar to the time period between the onset of symptoms and seeking of medical attention in other published studies (24-26).

In the majority of cases, fecal culture results were not used for treatment decisions because they were not available before the initiation of antimicrobial treatment and/or they were not available before the cessation of symptoms. For $78.9 \%$ of cases, fecal culture results were not available while they were symptomatic. This was due, in part, to the delay in seeking medical treatment, the relatively short duration of symptoms in the typical patient (mean 10.0 days) and the fastidious nature of Campylobacter, which can require up to five days to culture $(2,14,29)$. Therefore, the primary value of fecal culture in clinical campylobacteriosis may be to properly manage complicated or prolonged cases by adjusting therapy based on susceptibility results, as well as to meet public health needs (13). Information on the number, demographics and risk factors of cases is essential for ongoing public health programs (13).

Ontario has a universal health care system; therefore, access to physicians and submission of stool samples should not be influenced by the willingness or ability to pay for these services. However, the cost of antimicrobials is not universally covered and, therefore, the use of antimicrobials may be affected by cost. Because antimicrobials for oral therapy in humans are not available over the counter in Canada, and because all of the cases in the present study accessed the health care system, it was assumed that the antimicrobials taken were prescribed for this illness by a physician. Further research is required to determine the factors used by physicians when determining whether to prescribe antimicrobials for acute-onset diarrhea.

Only $22.2 \%$ of cases receiving antimicrobials in the present study began treatment after fecal test results were available. Although 10 different antimicrobials were used in the present study, those used after fecal results were available were primarily ERY, CIP and SXT, which was similar to previously published studies $(15,30)$. It should be noted that antimicrobials are not indicated for acute undifferentiated diarrhea in children due to the high proportion of cases with a viral etiology and the self-limiting nature of bacterial gastroenteritis in children (31). However, in the present study, 26 of $42(61.9 \%)$ cases who were $<5$ years of age were treated using antimicrobials. The three cases in this age group with reported daycare exposure were all treated using antimicrobials. With regard to severity of illness, none of the cases who were $<5$ years of age were hospitalized or were in the Fairly severe category; however, $46 \%$ were in the Quite mild category. This was similar to the results for all the cases, where those who were treated using antimicrobials did not differ from those that were not treated using antimicrobials with regard to severity of illness. However, cases in this dataset may be biased toward an increased level of severity due to the requirement for submission of a fecal sample. Empirical treatment of gastroenteritis in adults is only recommended in specific populations, such as international travellers $(22,32)$, yet, there was no significant difference in the proportion treated in cases with and without histories of international travel (ie, $\mathrm{P}>0.05$ ). With respect to fluoroquinolones, their use was of concern because it is a risk factor for fluoroquinolone-resistant Clostridium difficile-associated diarrhea (CDAD) (33). CDAD is an increasing public health concern in both hospital and community settings, illustrating the importance of the judicious use of fluoroquinolones (33). AMC, cephalexin and metronidazole were used for treatment in 11 cases in the present study, although these drugs are not indicated for undifferentiated gastroenteritis $(22,32)$. Although metronidazole is recommended for the treatment of Giardia infections, one of the distinguishing clinical features of Giardia infection is persistent diarrhea ( $>7$ days); however, six of eight patients treated using metronidazole initiated treatment at $<7$ days. The use of SXT for the clinical treatment of laboratoryconfirmed campylobacteriosis was unexpected due to the high proportion of Campylobacter isolates with resistance to SXT and the demonstrated lack of clinical effect $(34,35)$. SXT is recommended for the treatment of other enteric pathogens but not Campylobacter or undifferentiated diarrhea in international travellers $(13,22)$.

The prevalence of CIP and NAL resistance in the isolates from the present study $(<5 \%)$ was consistent with previously published research but was low compared with more recent Canadian and international data $(15,19,29,34,36-39)$. In a 1992/1993 hospital-based Montreal (Quebec) study (36), only 3.5\% of isolates were resistant to CIP, but the prevalence of resistance increased to $12.7 \%$ by 1997 . A study conducted in the US (15) found that in 2001, 18\% of C jejuni isolates were resistant and the adjusted OR for a Campylobacter isolate to be resistant to CIP was 2.5 times higher than in 1997. Similar increases in Campylobacter resistance to fluoroquinolones have been observed in other countries $(34,40)$. The only previous study using clinical cases from Ontario, conducted almost 20 years earlier (35), did not evaluate the resistance to CIP but found no resistance to NAL. The relatively low prevalence of resistance to CIP in the present study may be due to regional differences in specific risk factors including antimicrobial prescribing practices, antimicrobial access, travel, water supply and the prevalence of CIP resistance in Campylobacter isolated from retail poultry $(19,37,39)$. Case-control studies have consistently identified chicken consumption, in particular, as a major risk factor for campylobacteriosis (40-45). Additional research has estimated that the proportion of human campylobacteriosis cases that can be attributed to the consumption of chicken ranges from $20 \%$ to $80 \%$ (46-48). Therefore, CIP resistance in Campylobacter isolated from retail chicken may play an important role in CIP resistance in human campylobacteriosis. The prevalence of CIP resistance in Campylobacter isolated from retail chicken was sampled as an additional component to the current study and was also found to be quite low (1.9\%) (49). Antimicrobial use practices in poultry production in Canada are unknown but may impact antimicrobial resistance in Campylobacter from retail chicken (50). These results suggest that fluoroquinolone use in domestic poultry production during the time period of the present study may have been uncommon.

Differences in the populations studied may also have played a role in the observed disparity in resistance, because many studies only included isolates from hospitals or referral laboratories $(36,37,51)$. Hospitalized patients are more likely to have been treated using antimicrobials, including fluoroquinolones, and isolates from referral laboratories may not be representative.

In 2005, the breakpoint established by the CLSI for ERY was changed from $\geq 8 \mu \mathrm{g} / \mathrm{mL}$ to $\geq 32 \mu \mathrm{g} / \mathrm{mL}$; as a result, many relevant studies had described levels of resistance to ERY based on the lower breakpoint. In the present study, there were two isolates (1.6\%) that were resistant to ERY and both had an MIC of $>256 \mu \mathrm{g} / \mathrm{mL}$. Therefore, these isolates would be categorized as resistant at both the $\geq 8 \mu \mathrm{g} / \mathrm{mL}$ and $\geq 32 \mu \mathrm{g} / \mathrm{mL}$ 
breakpoints. Although differences in antimicrobial access may play a role in the high level of resistance to CIP in human isolates from some countries, this does not appear to result in high levels of resistance to ERY $(37,39,51,52)$. The prevalence of resistance to ERY at the current breakpoint was between $0 \%$ and $2.9 \%$ in other published studies (3537,39,51-54). The prevalence of resistance to CLI was also low, both in the present study and in previous studies, with the exception of the Guévremont study in Quebec where 10.3\% of isolates were resistant to CLI $(15,35,53,55,56)$. The two isolates in the present study that were resistant to ERY with an MIC of $>256 \mu \mathrm{g} / \mathrm{mL}$ were also resistant to CLI, which is consistent with a previously published Canadian study (35).

Differences in the panel of antimicrobials tested makes comparisons of multidrug resistance difficult between studies, and differences in isolation methodologies also make comparisons of individual resistance results difficult. In addition, the lack of standardized breakpoints used for Campylobacter makes comparisons problematic, unless MIC data are provided in a form that enables the recalculation of the proportion of resistant isolates $(39,51)$.

The incidence of campylobacteriosis per 100,000 people in the WDG health unit was similar to that found in the neighbouring Waterloo (Ontario) region (49.69 per 100,000 people) (57), in the province of Ontario (42.3 per 100,000 people, 1997 to 2001) (58) and nationally (34.9 cases per 100,000 people, 2001 to 2004) (59). The incidence of campylobacteriosis in the PD health unit was substantially higher than in the WDG health unit, which was expected because of the historically high reported incidence in this health unit. This may be related to differences in exposure to risk factors, which may include the presence of a chicken abattoir as a major employer in this region, because Campylobacter has been associated with occupational exposure to chicken processing (60). Moreover, there may be an increased proportion of rural properties with chickens and exposure to raw milk due to the presence of a farm-based religious community in the PD health unit area. The PD and WDG health units are located in different watersheds, which may result in a different level of exposure due to water supply. Differences in physician awareness of zoonoses and subsequent differences in levels of stool testing may also play a role.

The age distribution of the cases involved in the present study was consistent with the previously observed age distributions in these health units, and with other literature, although the substantial peak in children $<5$ years of age that was reported in some studies was not observed (Figure 1) $(29,59,61,62)$. It has been suggested that this peak may be due to an increased sampling frequency in young children with gastrointestinal illness compared with older children and adults $(14,61,62)$. It is possible that this increased sampling frequency in young children does not occur in these health units, possibly due to the length of time required to obtain fecal culture results and the shorter duration of clinical signs that have been found in children $<10$ years of age (26). Alternatively, the true incidence of Campylobacter infection in young children in this region may be lower than reported elsewhere.

Data from the present study were collected between 2002 and 2004. Antimicrobial use and antimicrobial resistance in these two health unit areas may have changed since that time.

\section{CONCLUSIONS}

Because antimicrobials are not indicated for undifferentiated gastroenteritis or campylobacteriosis in most cases that involve children, the high proportion of cases in the present study that were treated using antimicrobials ( $54 \%$ overall, $62 \%$ of children) is concerning. However, among cases that were treated using an antimicrobial considered efficacious against Campylobacter, approximately $95 \%$ of tested isolates were susceptible to that antimicrobial. This is not surprising considering the low levels of resistance found in the present study to ERY and CIP, although, in the majority of cases, treatment decisions were made before the availability of fecal culture results. Therefore, although the use of antimicrobials appeared to be quite high, the majority of cases were treated appropriately from a microbiological perspective. However, the value of this treatment is questionable considering the minimal impact expected on the illness, the potential increased risk for CDAD and the increased opportunity for the development of antimicrobial resistance. The low levels of antimicrobial resistance to CIP, ERY and NAL in Campylobacter from this region are encouraging. Prudent use practices should be promoted among physicians in family practice, walk-in clinics and emergency rooms to reduce the use of antimicrobials in the treatment of gastroenteritis in general and Campylobacter infection in particular, as well as to minimize the future development of resistance to these antimicrobials in Campylobacter species.

ACKNOWLEDGEMENTS: The authors acknowledge C Clarke and $\mathrm{J}$ de Grosbois for their help with questionnaire administration, the participating hospital and private laboratories for providing isolates, and S Brown and $\mathrm{K}$ Harris for speciation and antimicrobial susceptibility testing.

FUNDING: Funding for this project was obtained from the Ontario Ministry of Agriculture and Food and the Public Health Agency of Canada.

\section{REFERENCES}

1. Butzler JP. Campylobacter, from obscurity to celebrity. Clin Microbiol Infect 2004;10:868-76.

2. Murray PR, Rosenthal KS, Kobayashi GS, Pfaller MA. Medical microbiology. St Louis: Mosby, 1998.

3. Government of Canada. Notifiable diseases on-line. $<$ http://dsol-smed.phac-aspc.gc.ca/dsol-smed/ndis/index-eng.php> (Accessed November 1, 2012).

4. Centers for Disease Control and Prevention (CDC). Preliminary FoodNet data on the incidence of infection with pathogens transmitted commonly through food - 10 states, 2009. Morb Mortal Wkly Rep 2010;59:418-22.

5. Flint JA, Doré K, Majowicz SE, Edge VL, Sockett P. From stool to statistics: Reporting of acute gastrointestinal illnesses in Canada. Can J Public Health 2004:95:309-13.

6. Majowicz SE, Edge VL, Fazil A, et al. Estimating the underreporting rate for infectious gastrointestinal illness in Ontario. Can J Public Health 2005;96:178-81.

7. Thomas KM, Majowicz SE, Sockett PN, et al. Estimated numbers of community cases of illness due to Salmonella, Campylobacter and verotoxigenic Escherichia coli: Pathogen-specific community rates. Can J Infect Dis Med Microbiol 2006;17:229-34.

8. Swartz MN. Human diseases caused by foodborne pathogens of animal origin. Clin Infect Dis 2002;34(Suppl 3):S111-22.

9. Haagsma JA, Siersema PD, DE Wit NJ, Havelaar AH. Disease burden of post-infectious irritable bowel syndrome in the Netherlands. Epidemiol Infect 2010;138:1650-6.

10. Thabane M, Marshall JK. Post-infectious irritable bowel syndrome. World J Gastroenterol 2009;15:3591-6.

11. Allos BM. Campylobacter jejuni infections: Update on emerging issues and trends. Clin Infect Dis 2001;32:1201-6.

12. Blaser MJ, Engberg J. Clinical aspects of Campylobacter jejuni and Campylobacter coli infections. In: Nachamkin I, Szymanski CM, Blaser MJ, eds. Campylobacter, 3rd edn. Washington, DC: ASM Press, 2008:99.

13. Guerrant RL, Van Gilder T, Steiner TS, et al. Practice guidelines for the management of infectious diarrhea. Clin Infect Dis 2001;32:331-51.

14. Kapperud G, Lassen J, Ostroff SM, Aasen S. Clinical features of sporadic Campylobacter infections in Norway. Scand J Infect Dis 1992;24:741-9.

15. Gupta A, Nelson JM, Barrett TJ, et al. Antimicrobial resistance among Campylobacter strains, United States, 1997-2001. Emerg Infect Dis 2004;10:1102-9.

16. Nelson JM, Smith KE, Vugia DJ, et al. Prolonged diarrhea due to ciprofloxacin-resistant Campylobacter infection. J Infect Dis 2004;190:1150-7.

17. Schonberg-Norio D, Mattila L, Lauhio A, et al. Patient-reported complications associated with Campylobacter jejuni infection. Epidemiol Infect 2010;138:1004-11.

18. Helms M, Simonsen J, Olsen KEP, Molback K. Adverse health events associated with antimicrobial drug resistance in Campylobacter species: A registry-based cohort study. J Infect Dis 2005;191:1050-5. 
19. Engberg J, Neimann J, Nielsen EM, Aarestrup FM. Quinoloneresistant Campylobacter infections in Denmark: Risk factors and clinical consequences. Emerg Infect Dis 2004;10:1056-63.

20. Smith KE, Besser JM, Hedberg CW, et al. Quinolone-resistant Campylobacter jejuni infections in Minnesota, 1992-1998. N Engl J Med 1999;340:1525-32.

21. Canadian Integrated Program for Antimicrobial Resistance Surveillance (CIPARS) 2007. Guelph: Government of Canada, 2010.

22. Lo Re V. Infectious diseases: Hot topics. Philadelphia: Hanley and Belfus, 2004

23. Karmali MA, Fleming PC. Campylobacter enteritis in children. J Pediatr 1979;94:527-33.

24. Anders BJ, Lauer BA, Paisley JW, Reller LB. Double-blind placebo controlled trial of erythromycin for treatment of Campylobacter enteritis. Lancet 1982;1:131-2.

25. Pai CH, Gillis F, Tuomanen E, Marks MI. Erythromycin in treatment of Campylobacter enteritis in children. Am J Dis Child 1983;137:286-8.

26. Mandal BK, Ellis ME, Dunbar EM, Whale K. Double-blind placebocontrolled trial of erythromycin in the treatment of clinical Campylobacter infection. J Antimicrob Chemother 1984;13:619-23.

27. Public health considerations of infectious diseases in child day care centers. The Child Day Care Infectious Disease Study Group. J Pediatr 1984;105:683-701.

28. Ashkenazi S, Danziger Y, Varsano Y, Peilan J, Mimouni M. Treatment of Campylobacter gastroenteritis. Arch Dis Child 1987;62:84-5.

29. Blaser MJ. Epidemiologic and clinical features of Campylobacter jejuni infections. J Infect Dis 1997;176(Suppl 2):S103-5.

30. Kapperud G, Aasen S. Descriptive epidemiology of infections due to thermotolerant Campylobacter spp. in Norway, 1979-1988. APMIS 1992;100:883-90.

31. King CK, Glass R, Bresee JS, Duggan C; Centers for Disease Control and Prevention. Managing acute gastroenteritis among children: Oral rehydration, maintenance, and nutritional therapy. MMWR Recomm Rep 2003;52:1-16.

32. Aberg JA, Goldman MP, Gray LD, Long JK. Infectious diseases handbook. Canada: Lexi-Comp, 2006.

33. Razavi B, Apisarnthanarak A, Mundy LM. Clostridium difficile: Emergence of hypervirulence and fluoroquinolone resistance. Infection 2007;35:300-7.

34. Luber P, Wagner J, Hahn H, Bartelt E. Antimicrobial resistance in Campylobacter jejuni and Campylobacter coli strains isolated in 1991 and 2001-2002 from poultry and humans in Berlin, Germany. Antimicrob Agents Chemother 2003;47:3825-30.

35. Karmali, De Grandis, Fleming. Antimicrobial susceptibility of Campylobacter jejuni with special reference to resistance patterns of Canadian isolates. Antimicrob Agents Chemother 1981;19:593-7.

36. Gaudreau C, Gilbert H. Antimicrobial resistance of clinical strains of Campylobacter jejuni subsp jejuni isolates from 1985 to 1997 in Quebec, Canada. Antimicrobial Agents Chemother 1998;42:2106-8.

37. Levesque S, Frost E, Michaud S. Comparison of antimicrobial resistance of Campylobacter jejuni isolated from humans, chickens, raw milk, and environmental water in Quebec. J Food Prot 2007;70:729-35.

38. Johnson J, McMullen L, Hasselback P, Louie M, Jhangri G, Saunders L. Risk factors for ciprofloxacin resistance in reported Campylobacter infections in southern Alberta. Epidemiol Infect 2007;136:903-12.

39. Boonmar S, Morita Y, Fujita M, et al. Serotypes, antimicrobial susceptibility, and gyr A gene mutation of Campylobacter jejuni isolates from humans and chickens in Thailand. Microbiol Immunol 2007;51:531-7.

40. Engberg J. Contributions to the epidemiology of Campylobacter infections. A review of clinical and microbiological studies. Dan Med Bull 2006;53:361-89.

41. Domingues AR, Pires SM, Halasa T, Hald T. Source attribution of human campylobacteriosis using a meta-analysis of case-control studies of sporadic infections. Epidemiol Infect 2012;140:970-81.

42. Olson CK, Ethelberg S, Van Pelt W, Tauxe RV. Epidemiology of Campylobacter jejuni infections in industrialized nations.
In: Nachamkin I, Szymanski CM, Blaser MJ, eds. Campylobacter, 3rd edn. Washington, DC: ASM Press, 2008:163.

43. Friedman CR, Hoekstra RM, Samuel M, et al. Risk factors for sporadic Campylobacter infection in the United States: A casecontrol study in FoodNet sites. 2004;38(Suppl 3):S285-96.

44. Neimann J, Engberg J, Molbak K, Wegener HC. A case-control study of risk factors for sporadic Campylobacter infections in Denmark. Epidemiol Infect 2003;130:353-66.

45. Effler P, Ieong M, Kimura A, et al. Sporadic Campylobacter jejuni infections in Hawaii: Associations with prior antibiotic use and commercially prepared chicken. J Infect Dis 2001;183:1152-5.

46. de Haan CP, Kivisto RI, Hakkinen M, Corander J, Hanninen ML. Multilocus sequence types of Finnish bovine Campylobacter jejuni isolates and their attribution to human infections. BMC Microbiol 2010;10:200.

47. EFSA Panel on Biological Hazards. Scientific opinion on quantification of risk posed by broiler meat to human Campylobacteriosis in the EU. EFSA J 2010;8:1437-526.

48. Mullner P, Jones G, Noble A, Spencer SE, Hathaway S, French NP. Source attribution of food-borne zoonoses in New Zealand: A modified Hald model. Risk Anal 2009;29:970-84.

49. Deckert A, Valdivieso-Garcia A, Reid-Smith R, et al. Prevalence and antimicrobial resistance in Campylobacter spp. isolated from retail chicken in two health units in Ontario. J Food Prot 2010;73:1317-24.

50. Government of Canada. Surveillance bulletin - Canadian Integrated Program for Antimicrobial Resistance Surveillance (CIPARS): Emergence of ciprofloxacin-resistant Campylobacter in retail chicken in British Columbia and Saskatchewan. <www.phac-aspc.gc.ca/cipars-picra/bulletin-eng.php> (Accessed July 3, 2012).

51. Hakanen AJ, Lehtopolku M, Siitonen A, Huovinen P, Kotilainen P. Multidrug resistance in Campylobacter jejuni strains collected from Finnish patients during 1995-2000. J Antimicrob Chemother 2003;52:1035-9.

52. Gaudreau C, Gilbert H. Antimicrobial resistance of Campylobacter jejuni subsp. jejuni strains isolated from humans in 1998 to 2001 in Montreal, Canada. Antimicrob Agents Chemother 2003;47:2027-9.

53. Lariviere LA, Gaudreau CL, Turgeon FF. Susceptibility of clinical isolates of Campylobacter jejuni to twenty-five antimicrobial agents. J Antimicrob Chemother 1986;18:681-5.

54. Taylor DE, Chang N, Garner RS, Sherburne R, Mueller L. Incidence of antibiotic resistance and characterization of plasmids in Campylobacter jejuni strains isolated from clinical sources in Alberta, Canada. Can J Microbiol 1986;32:28-32.

55. Sjogren E, Kaijser B, Werner M. Antimicrobial susceptibilities of Campylobacter jejuni and Campylobacter coli isolated in Sweden: A 10-year follow-up report. Antimicrob Agents Chemother 1992;36:2847-9.

56. Guevremont E, Nadeau E, Sirois M, Quessy S. Antimicrobial susceptibilities of thermophilic Campylobacter from humans, swine, and chicken broilers. Can J Vet Res 2006;70:81-6.

57. Keegan VA, Majowicz SE, Pearl DL, et al. Epidemiology of enteric disease in C-EnterNet's pilot site - Waterloo region, Ontario, 1990 to 2004. Can J Infect Dis Med Microbiol 2009;20:79-87.

58. Lee MB, Middleton D. Enteric illness in Ontario, Canada, from 1997 to 2001. J Food Prot 2003;66:953-61.

59. Ruzante JM, Majowicz SE, Fazil A, Davidson VJ. Hospitalization and deaths for select enteric illnesses and associated sequelae in Canada, 2001-2004. Epidemiol Infect 2011;139:937-45.

60. Wilson IG. Airborne Campylobacter infection in a poultry worker: Case report and review of the literature. Commun Dis Public Health 2004;7:349-53.

61. Skirrow MB. A demographic survey of Campylobacter, Salmonella and Shigella infections in England. A public health laboratory service survey. Epidemiol Infect 1987;99:647-57.

62. Samuel MC, Vugia DJ, Shallow S, et al. Epidemiology of sporadic Campylobacter infection in the United States and declining trend in incidence, FoodNet 1996-1999. 2004;38(Suppl 3):S165-74. 


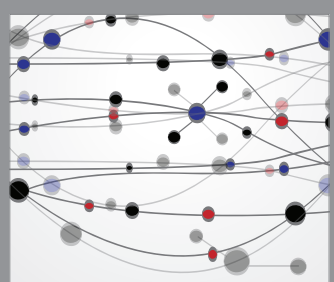

The Scientific World Journal
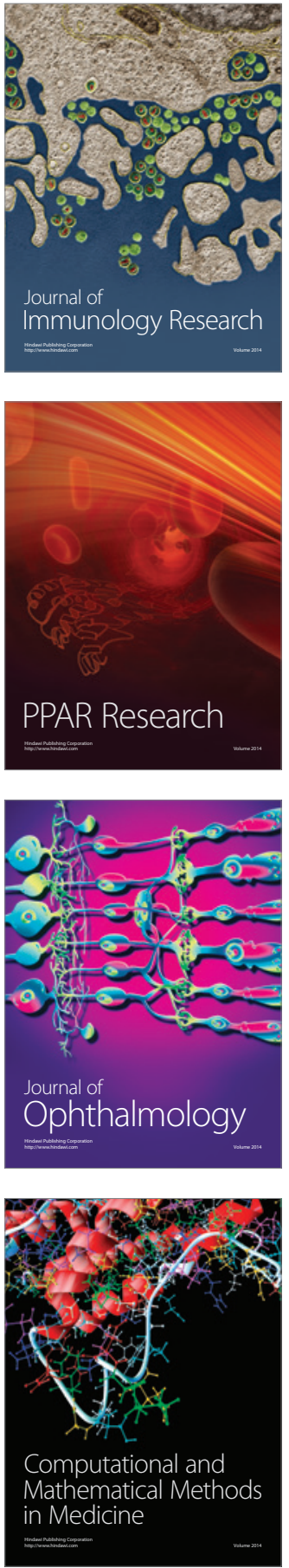

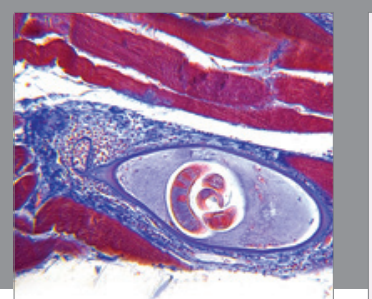

Gastroenterology Research and Practice

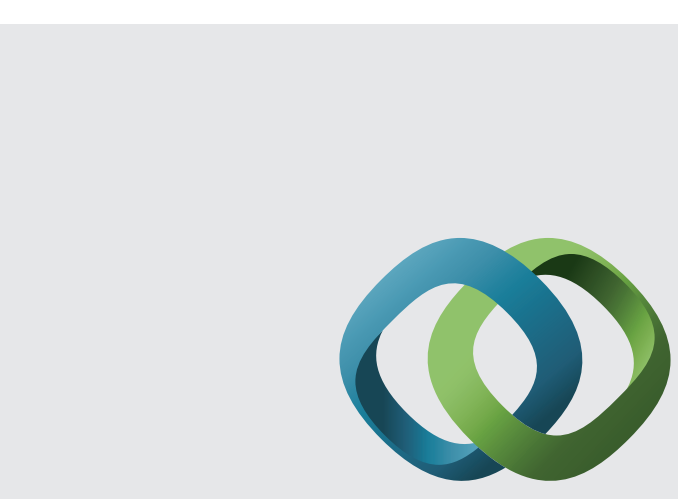

\section{Hindawi}

Submit your manuscripts at

http://www.hindawi.com
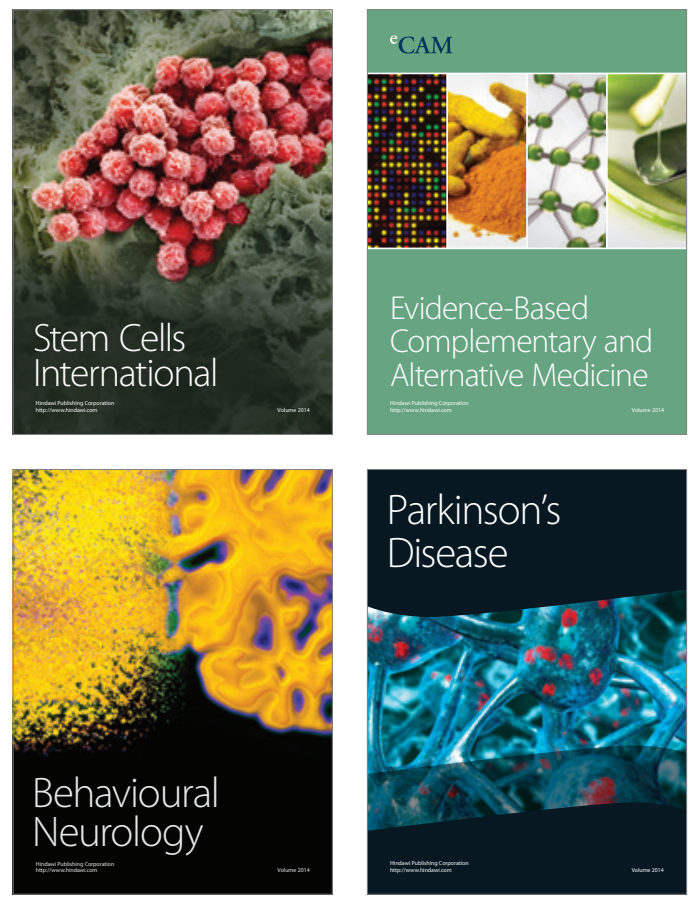
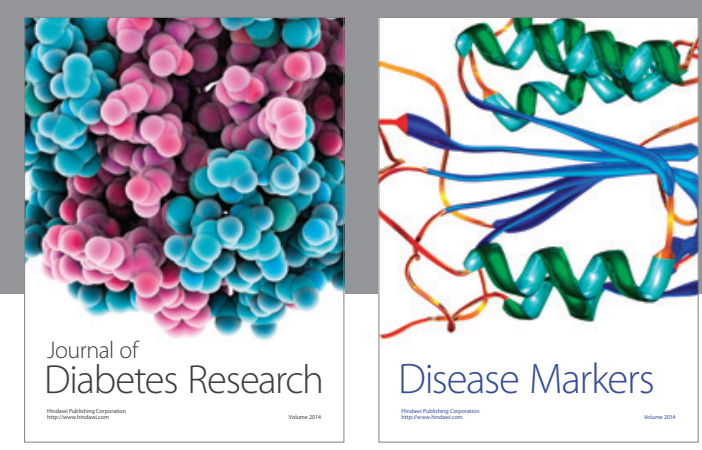

Disease Markers
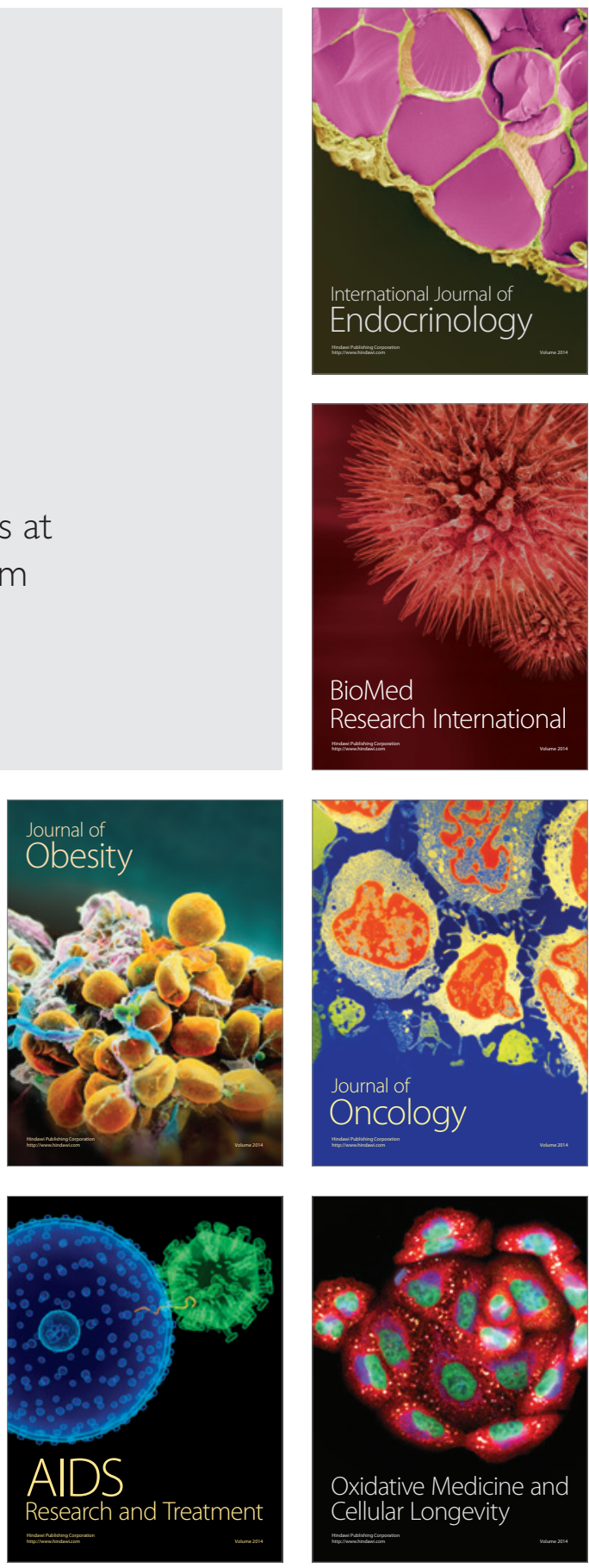